\title{
A Review on Independent Suspension System of Light Commercial Vehicle
}

\author{
S.S.Khode ${ }^{1}$, A.A. Satam ${ }^{1}$, A.B.Gaikwad ${ }^{2}$ \\ ${ }^{1}$ (Department of Mechanical Engineering, RITP, Pune, India) \\ ${ }_{2}^{2}$ (Department of Mechanical Engineering, D. Y. Patil School of Engineering, S.P.Pune University, India)
}

\begin{abstract}
Suspension system is the necessary part in the automobile vehicle. Suspension system provide comfort ride to the passengers. Suspension systems have been widely applied to vehicles, from the horse-drawn carriage with flexible leaf springs fixed in the four corners, to the modern automobile with complex control algorithms. The suspension of a road vehicle is usually designed with two objectives to isolate the vehicle body from road irregularities and to maintain contact of the wheels with the roadway. The suspension link allows wheels to rise and fall on their own without affecting the opposite wheel. In this case, the wheels are either not connected at all or are connected through universal joints with a swing axle. Suspensions with other devices, such as anti-roll bar that link the wheels in some way are still classed as independent suspension link. Suspension system absorbs the unnecessary vibration which applied on the upward from road irregularities. Here in this paper we will review on independent suspension system
\end{abstract}

Keywords - Suspension, Wishbone. Light Commercial Vehicle.

\section{INTRODUCTION}

An important part of your vehicle's suspension system is the control arms as they manage the motion of the wheels in relation to cars body. Too much movement and passengers will soon find themselves feeling car sick, not to mention the wear and tear that worn out control arms do to the rest of your suspension system. The suspension system of your car cannot do its designated task alone. This suspension system must have reliable and advanced suspension components to make sure that it will function perfectly. A good example of this part that is very crucial for the suspension system of your car is the control arm. The control arm is one of the most crucial components of the suspension system of your car. This control arm has the function or task in managing the motion of the wheels of your car in proper relation with the chassis or the body of it. Made from quality and durable materials like quality steel or iron, this control arm is a must for all vehicles on the road. Without the help of this control arm on the suspension system of your car, it is expected that you can encounter annoying vibrations and unwanted driving irregularities that could sometimes lead to road accidents like head to head collision with another car or obstruction on the road. Make sure that control arm is always in proper working condition. This can be done by doing regular checkups and maintenance [3]. According to Mr. Prashanthasamy R.M.T [7] et al. "Design and Modal Analysis of Lower Wishbone Suspension Arm Using FE Approach",In automobile industries wishbone arm is major component in this suspension system which is of independent suspension. The major function of arm is to maintain smooth suspension condition. The arms are usually upper and lower arm. The loads will be acting more on lower arm than upper arm because of its position. These load conditions on lower arm leads to maximum bending. Presently in the most of the automobiles industries are using suspension arm of hallow and idled of steel AISI 1040 material. Hence in this thesis the study is made on existing design with aluminum alloy. The 3D model will be generated by Catia V5, the FE model will be generated by HyperMesh and the static and dynamic analysis will be conducted by Abaqus. According to Dr. S. Balamurugan [8] et al."Design and Analysis of Lower Control ARM" April 2016. The main objective of this paper is to model and to perform structural analysis of a LOWER CONTROL ARM (LCA) used in the front suspension system, which is a sheet metal component. LCA is modeled in Pro-E software for the given specification. To analyze the LCA, CAE software is used. The load acting on the control arm are dynamic in nature, buckling load analysis is essential. The existing design has been modified, by reducing the thickness of the existing profile and the reinforcement plate has been proposed. The optimization of lower control arm is done by applying the DOE method. The parameters are identified. Finally mass of the control arm has been reduced up to $13.8 \%$ when compared with existing model. This project can be extended to satisfy the requirements as the key objectives such as, Implementing new design changes in the existing model can be done, Identifying more materials for the proposed design and new design ,Increasing the number of levels of the response. According to Himanshu Deshwal [9] et al. "Finite Element Analysis and Geometric Optimization of 
Double Wishbone Pushrod Actuation Suspension System of "SUPRA SAEINDIA" Vehicle", this work present research on the double wishbone pushrod actuation suspension system of SUPRA SAEINDIA Vehicle is optimized through FEA by using ANSYS as analysis tools. The objective of this research is to analyses in terms of component load and stress study, a quarter vehicle of front wheel drive for typical double wishbone suspension system using multi-body simulation system (MBS) together with computer aided design and analysis environment (CAD \&CAE).

The main role of suspension system is as follows:

1. It supports the weight of the vehicle

2. Provides a smoother ride for the passengers

3. Protects the vehicle from damage

4. Keeps the wheels firmly pressed to the ground for better traction

5. It isolates the vehicle from road shocks

There are three basic components in any suspension system:

1. Springs

2. Dampers

3. Anti-sway bars

The following types of suspension systems are generally available in the market: 1. Mechanical Suspension System: i) Independent Suspension

1) Leaf Spring Suspension

2) MacPherson Suspension

3) Wishbone Suspension

ii) Dependent Suspension

1) Rigid Axle Suspension

2) Electric Suspension System

3) Magnetic Suspension System

\section{SELECTION OF SUITABLE SUSPENSION SYSTEM}

The selection of the suspension system which will best satisfy the requirements of an ATV was carried out. Out of the many available suspension systems in the market, the Double Wishbone Suspension System was selected for the ATV (All Terrain). This selection was done based on the following basic parameters:

1. Load bearing capacity

2. Flexibility

3. Cost

4. Technical aspects: Camber, Stiffness, Rolling

5. Availability of parts and components

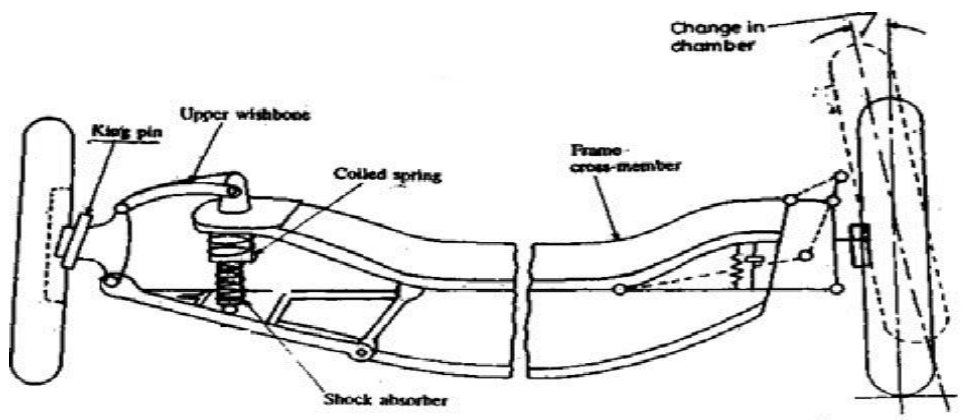

Fig.1 Independent suspension link

III. BASIC SUSPENSION PARTS

Spring: The spring is the core of nearly all suspension systems. It's the component that absorbs shock forces while maintaining correct riding height. The increased effect of shock impairs the vehicle's handling the amount of deflection exhibited under a specific load. A mounting plate welded to the lower arm serve as a lower spring seat. The upper seat is bolted to the strut piston rod. A bearing or rubber bushing in the upper mount permits the spring and strut to turn with the motion of the wheel as it steered. 
Shock Absorber: Shock absorber damp or control motion in a vehicle. If unrestrained, spring continue expanding andcontracting after a blow until all energy is absorbed. Shock absorber can be mounted vertically or at an angle. Anglemounting of shock absorbers improves vehicle stability and dampens accelerating and breaking torque. Because the lower control arm and ball joint are retained. The control arm serves as the lower locator of the suspension.

Ball Joint: A ball joint connects the steering knuckle to the control arm, allowing it to pivot on the control arm duringsteering. Ball joint also permit up and down movement of the control arm as the suspension reacts to road conditions.This ball joint are load caring and supports the car weight it also called tension loaded or compression loaded ball joint.

Bump Stop: Bump stop are located on lower control arm and it avoid direct contact of arm with chassis/body while car movement upward (jounce) and downward (rebound). Figure 2 shows the basic parts of wishbone suspension system.

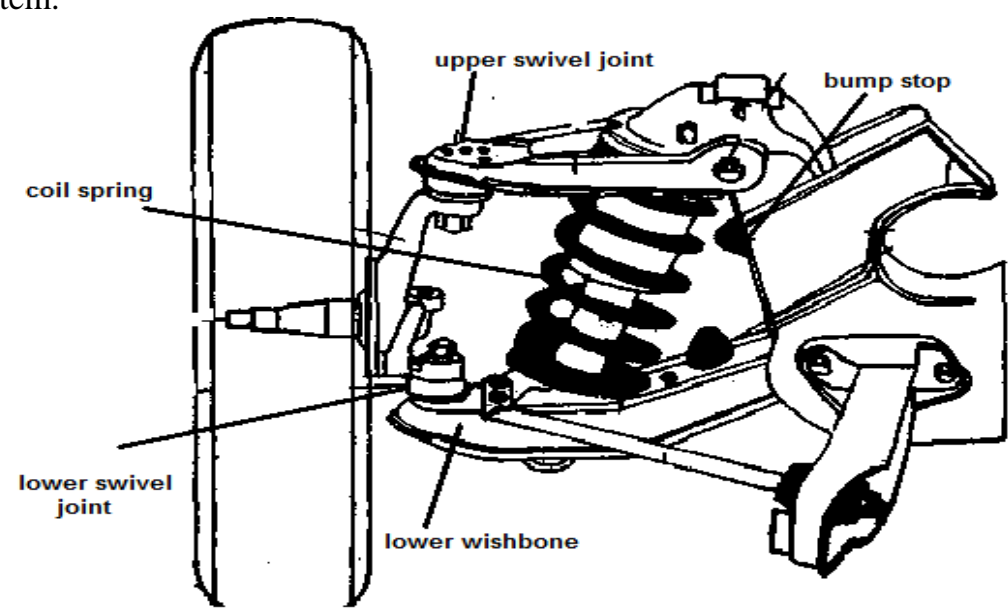

Fig.2 Parts of independent suspension link

\subsection{Constructional Exploded view}

In automobiles, double (or "upper and lower A-arm") suspension is an independent suspension design using two parallel wishbone-shaped arms to locate the wheel. Each wishbone or arm has two mounting points to the chassis andone joint at the knuckle. The shock absorber and coil spring mount to the wishbones to control vertical movement. Double wishbone designs allow the engineer to carefully control the motion of the wheel throughout suspension travel, controlling such parameters as camber angle, caster angle, toe pattern, and roll center height, scrub radius, scuff and more. Figure 3 shows the exploded View of Double Wishbone Suspension.

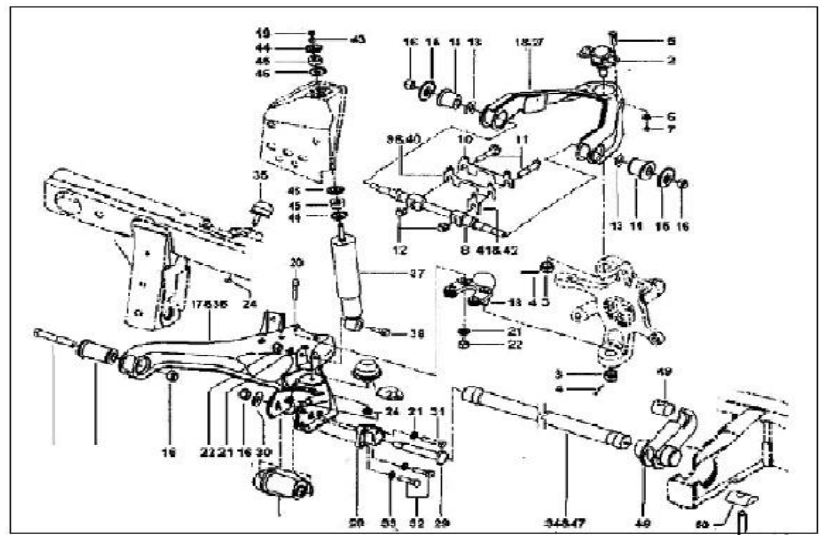

Fig.3 Exploded View of Double Wishbone Suspension

The suspension consists of a pair of upper and lower lateral arm, roughly horizontal. The upper arm is usually shorter

to induce negative camber as the suspension jounces (rises). When the vehicle is in a turn, body roll results in positive camber gain on the outside wheel. The outside wheel also jounces and gains negative camber due to the 
short upper arm. The suspension designer attempts to balance these two effects to cancel out and keep the tire perpendicular to the ground. This is especially important for the outer tire because of the weight transfer to this tire during a turn. Between the outboard ends of die arms is a knuckle with a spindle or hub which carries the wheel bearing and wheel. Knuckles with an integral spindle usually do not allow the wheel to be driven. A bolt on hub design is commonly used if the wheel is to be driven. In order to resist fore-aft loads such as acceleration and braking, the arms need two bushings or ball joints at the body. At the knuckle end, single ball joints are typically used, in which case the steering loads have to be taken via a steering arm, and the wishbones look A or L-shaped. An L-shaped arm is generally preferred on passenger vehicles because it allows a better compromise of handling and comfort to be tuned in. The bushing in line with the wheel can be kept relatively stiff to effectively handle cornering loads while the off-line joint can be softer to allow the wheel to recess under fore aft impact loads. For a rear suspension, a pair of joints can be used at both ends of the arm, making them more $\mathrm{H}$-shaped in plain view. In front view, the suspension is a 4-bar link, and it is easy to work out the camber gain and other parameters for a given set of bush locations. The various bushes do not have to be on horizontal axes, parallel to the vehicle center line.

\section{TYPES OF THE SUSPENSION SYSTEM}

The suspension system is always derived by some mechanical way. Generally speaking, the designs of the suspension systems are classification in two main groups

1. Dependent suspension system (solid axle) and

2. Independent suspension system.

Dependent suspension system (solid axle): Dependent suspension system is the system in which two wheels (front or rear) are connected to each other by one continues rod called as trailing rod. In this system if any bump or potholes disturb to one wheel automatically pair wheel also affected because of trailing rod. The trailing rod is shown by arrow in figure 4 .

Independent suspension system: The independent suspension system, allows one wheel to move upward and downward with a minimum effect on the other wheel (Figure 5). Mostly of the passenger cars and light truck use independent front suspension system, because provide much more space for installing vehicle engine, allow much more displacement of wheel, better resistance in steering vibration (wobble and shimmy) as well as offer higher performance in passenger comfort [1]

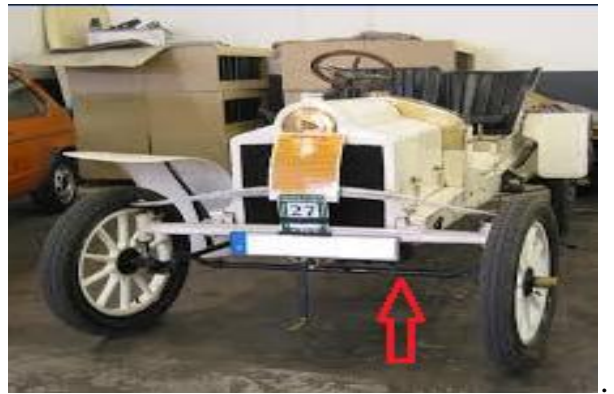

Fig.4.Old vehicles dependent system

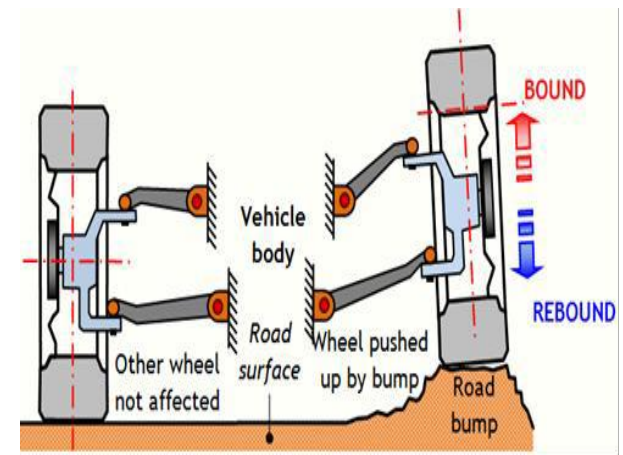

Fig.5.The independent suspension system (front view)

\section{DESIGN OF A-TYPE LOWER SUSPENSION ARM}

Design of LSA is the preliminary step to design the suspension system. Initially, the material may selected using Pugh's Concept of Optimization. Based on the properties of the selected material, the allowable stress is calculated using sheer stress theory of failure. The designed LSA are modeled using software and then analyzed using Hyper mesh or ANSYS software to find the maximum stress and maximum deflection in the LSA. Material Selection of LSA Material selection is the very important and starting point of any design and fabrication point of view. The strength of the material should be well enough to withstand all the loads acting on it in steady motion. The material selection also depends on number of factors such as carbon content, material properties, availability and the most important parameter is the cost. Initially, three materials may considered based on their availability in the market- AISI 1018, AISI 1040 and AISI 4130. By using Pugh's concept of optimization, we may chosen AISI 1040 for the wishbones or lower control arm. The main criteria were to have better material strength and lower weight along with optimum cost of the material.Pugh's Concept is a method for concept selection using a scoring matrix called the Pugh Matrix. It is implemented by establishing an 
evaluation team, and setting up a matrix of evaluation criteria versus alternative embodiments. This is the scoring matrix which is a form of prioritization matrix. Usually, the options are scored relative to criteria using a symbolic approach (one symbol for better than, another for neutral, and another for worse than baseline). These get converted into scores and combined in the matrix to yield scores for each option [3].

Design parameters: In case of vehicle in actual running conditions forces acting on it are of dynamic in nature and changes as per driving conditions. Various longitudinal forces are acting due to braking and acceleration while lateral forces acting due to cornering of vehicle. In order to make preliminary analysis steady state operating conditions may assumed. The assumptions made are smooth road conditions, steady state cornering and constant grade.

1) Vertical Loads acting on wheel:

In order to determine forces acting on lower control arm, following critical situations are considered. For above condition, load acting on front outerwheel is given by following formula.[2]

a)Vehicle at the instant of braking on downhill grade:

(Wfo) brak=(1/2L) [ W $(\mathrm{H} \operatorname{Sin} \Theta+\mathrm{C} \operatorname{Cos} \Theta)+$ m.a.H] $(1)$

Where, (Wfo) brakis breaking force on outside wheel.

b) Vehicle at the instant of cornering:

For above condition, load acting on front outer wheel is

given by following formula,

$(\mathrm{Wfo}) \operatorname{corn} .=(\mathrm{W} / 2 \mathrm{a})\left[(\mathrm{V} 2 / 2 * \mathrm{~g})\left(\mathrm{a} * \operatorname{Sin} \Theta+2 \mathrm{H}^{*} \operatorname{Cos} \Theta\right)+\right.$

$\left(\right.$ a. $\left.\left.\operatorname{Cos} \Theta-2 \mathrm{H}^{*} \operatorname{Sin} \beta\right)\right](2)$

Where, (Wfo)corn is cornering force on outside wheel.

]

2) Lateral Loads acting on Wheel

while vehicle taking turn, lateral forces acts on it which is

given by

(L)fo $=\mu *(\mathrm{~W})$ total (3)

Where, $(\mathrm{W})$ total $=($ Wfo $)$ brak+ $($ Wfo $)$ corn $(4)$

3) Forces acting on lower control arm

Let Rx and Ry be the maximum forces at the center of contact patch of front tire as shown in figure 6 and 7 .

Let Px, Py and Qx, Qybe the reaction forces acting on lower control arm as shown in figure 7. The reaction forces (Px, Py and Qx, Qy.) acting on lower control arm was found out by using equilibrium equation of mechanics.

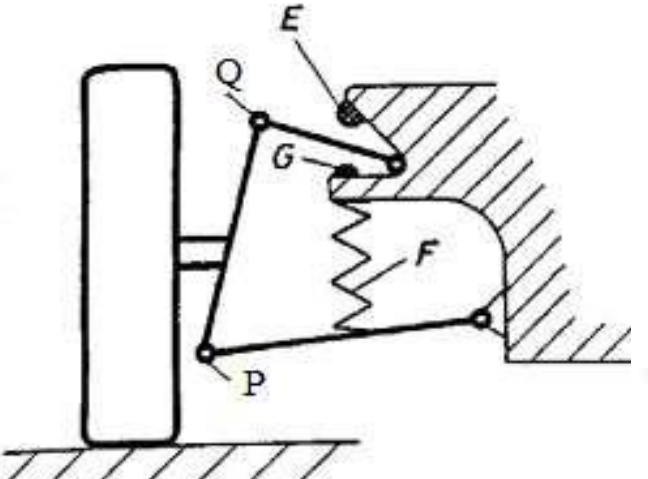

Fig 6: Suspension diagram

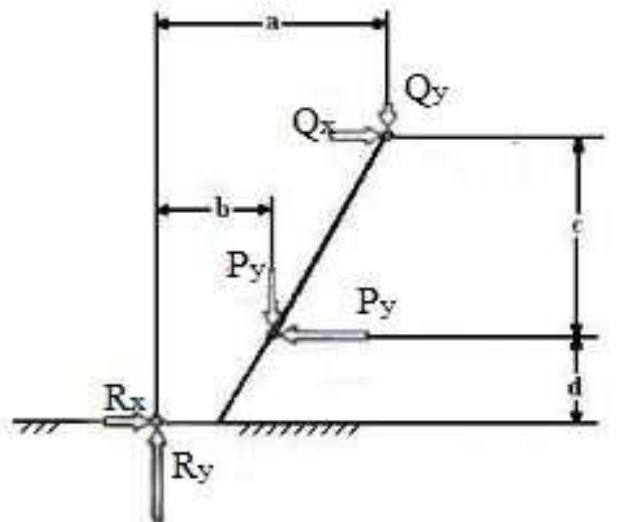

Fig 7: Forces on suspension

\section{CONCLUSION}

The general function of control arms is to keep the wheels of a motor vehicle from uncontrollably swerving when the road conditions are not smooth. The control arm suspension normally consists of upper and lower arms. The upper and lower control arms have different structures based on the model and purpose of the vehicle. By many accounts, the lower control arm is the better shock absorber than the upper arm because of its position and load bearing capacities. It has an " $\mathrm{A}$ " shape on the bottom known as wishbone shape which carries most of the load from the shock received. The lower control arm takes most of the impact that the road has on the wheels of the motor vehicle. It either stores that impact or sends it to the coils of the suspension depending on its shape. During the actual working condition, the maximum load is transferred from upper wishbone arm to 
the lower arm which creates possibility of failure in the arm. Similarly, impact loading produces the bending which is not desirable. Existing design lower control arm for recent light commercial are overdesigned which increase the unsprang weight so there is a scope for optimization. Hence it is essential to focus on the stress strain analysis study of lower wishbone arm to improve and modify the existing design.

\section{REFERENCES}

[1] C. M. Chaudhari, M. V. Sulakhe, "Finite element analysis and testing of suspension arm," National Conference on Advances in Mechanical Engineering, 03 - 05January, 2011.

[2] V. Kulkarni,. "Finite Element Analysis and Topology Optimization of Lower Arm of Double Wishbone Suspensionusing RADIOSS and Optistruct" International Journal of Science and Research (IJSR).

[3] Ragnar Ledesma,Shan Shih, "Heavy and Medium Duty Vehicle Suspension-Related Performance Issues and Effective Analytical Models for System Design Guide," SAE TECHNICAL PAPER SERIES, 199901-3781.

[4] J. Y. Wong, "Theory of Ground Vehicles", John Wiley \& Sons, Third Edition.

[5] Giancarlo Genta, Lorenzo Morello, "The automotive chassis," volume 1: component design, springer science publication.

[6] Thomas D. Gillespie, "Fundamental of vehicle dynamics",society of automotive engineer Inc.

[7] Prashanthasamy . "Design and Modal Analysis of Lower Wishbone Suspension Arm Using FE Approach" Imperial Journal of Interdisciplinary Research (IJIR) Vol-2, Issue-9, 2016.

[8] M. Sridharan et al. "Design and Analysis of Lower Control ARM" International Journal of Innovative Research in Science, 5, Issue 4 April 2016.

[9] H. Deshwal. "Finite Element Analysis and Geometric Optimization of Double Wishbone Pushrod Actuation Suspension System of "SUPRA SAEINDIA" Vehicle" SSRG International Journal of Mechanical Engineering (SSRG-IJME) - volume 3 Issue 5 - May 2016. 